\title{
Subsynchronous Resonance and FACTS-Novel Control Strategy for Its Mitigation
}

\author{
Doan Duc Tung $\mathbb{D}^{1},{ }^{1}$ Le Van Dai $\mathbb{D}{ }^{2},{ }^{2}$ and Le Cao Quyen $\mathbb{D}^{3,4}$ \\ ${ }^{1}$ Faculty of Engineering and Technology, Quy Nhon University, Binh Dinh, Vietnam \\ ${ }^{2}$ Faculty of Electrical Engineering Technology, Industrial University of Ho Chi Minh City, Ho Chi Minh City, Vietnam \\ ${ }^{3}$ Department for Management of Science and Technology Development, Ton Duc Thang University, Ho Chi Minh City, Vietnam \\ ${ }^{4}$ Faculty of Electrical and Electronics Engineering, Ton Duc Thang University, Ho Chi Minh City, Vietnam
}

Correspondence should be addressed to Le Cao Quyen; lecaoquyen@tdtu.edu.vn

Received 23 February 2019; Revised 12 May 2019; Accepted 11 June 2019; Published 14 July 2019

Academic Editor: Wei-Qiang Zhang

Copyright (C) 2019 Doan Duc Tung et al. This is an open access article distributed under the Creative Commons Attribution License, which permits unrestricted use, distribution, and reproduction in any medium, provided the original work is properly cited.

\begin{abstract}
The subsynchronous resonance (SSR) is an important problem in the power system, and especially the series compensated transmission lines may cause SSR in the turbine generators, such that it leads to the electrical instability at subsynchronous frequencies and potential turbine-generator shaft failures. Taking the Vietnamese Vungang thermal plants as an example, a shaft failure of Vungang I thermal power unit has occurred on November 24, 2015, due to SSR. The main cause for this failure is a resonance caused by the series capacitors on the $500 \mathrm{kV}$ grid. This paper analyzes the SSR based on the location of shaft cracks and turbine generator mode shape for Vungang I and II thermal power plants. On the basis of that, it develops a novel control strategy for each Flexible AC Transmission system (FACTS) device as the thyristor controlled series compensator (TCSC), static VAR compensator (SVC), and static synchronous compensator (STATCOM). Then they are comparable to one another in order to choose a feasible solution for mitigating the SSR. The effectiveness of the proposed control strategy is verified via time domain simulation of the Vietnamese 500/220 kV transmission system using EMTP-RV and PSS/E programs. The obtained results show that the proposed strategy for SVC can be applied to immediately solve the difficulties encountering in the Vietnamese power system.
\end{abstract}

\section{Introduction}

As known, the series capacitor compensation has been widely used in the AC transmission systems as an economical alternative for different purposes such as bringing many benefits for the economy, increasing the capability of transferring power and the stability of the transmission line, sharing the load between the parallel transmission lines, and insuring the power system stability $[1,2]$. However, the use of series compensation may cause some new problems to power system operation. One of these problems is potentiality of subsynchronous resonance (SSR) that may lead to the torsional oscillations of turbine generator shaft system. The failure on the generator turbine shaft and the instability of the power system at oscillation frequencies lower than the normal system frequency result from SSR [3]. The main connection of SSR is the possibility of breaking the generator turbine shaft due to the torsional stress. This destruction could be an outcome, which is an accumulative process of the torsional oscillation for either a long time having slow amplitude or a short time having high amplitude. The shaft failures at Vungang I thermal power plant (TPP) led to the advancements in understanding the SSR phenomenon as well as explaining the interaction between series capacitor compensated lines and the torsion mode of turbine-generators.

Vungang I TPP is located in the Vungang industrial zone, Kyloi commune, Kyanh district, Hatinh province in Vietnam, consisting of two turbines with a total capacity of 1,200 MW; the first unit is operated on December 31, 2014, and the second unit is operated on May 12, 2015, respectively. As has been shown by Toshiba engineers' inspection, the first unit turbine and generator rotors showed large vibrations due to 


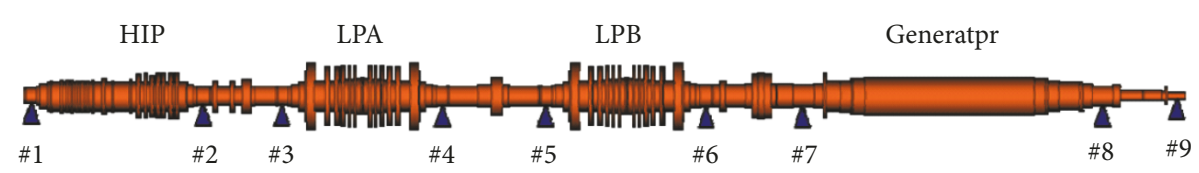

(a)

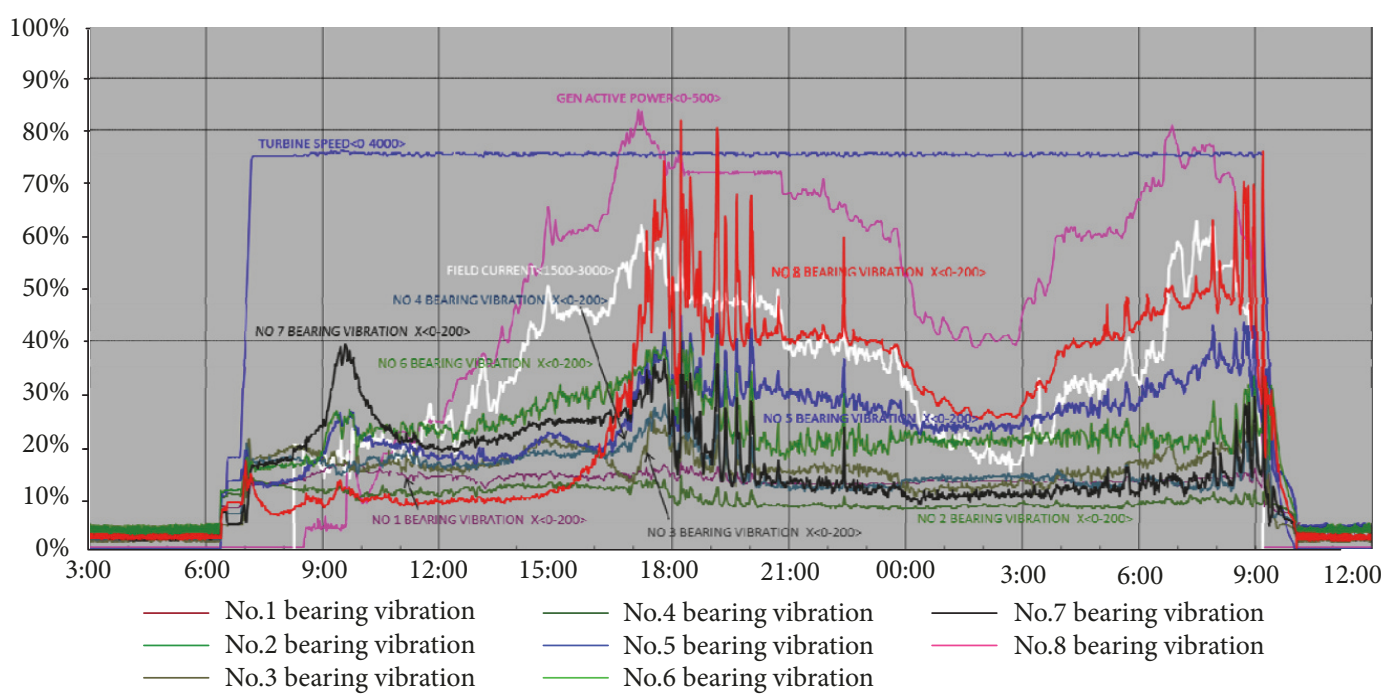

(b)

FIgURE 1: The first unit turbine of Vungang I: (a) Rotor shaft system of turbine generator rotor. (b) Operation data record on 24th to 25th, Nov. 2015.

SSR that occurred on November, 24, 2015. Figure 1 shows the operation data of the first unit turbine from 24th to 25th November 2015. The behavior of the vibration was unstable, and in particular the vibration of No. 8 bearing (red line) exceeded $100 \mu \mathrm{mp}^{-} \mathrm{p}$. The large vibration of No. 8 bearing was reproduced and $\mathrm{H} 2$ gas leakage from generator at No. 7 bearing was observed, and the result shows that several heavy cracks were observed on generator No. 7 journal of the first unit generator; it can be shown in Figure 2. According to this result, the subsynchronous resonance (SSR) is judged as the root cause.

In 1937, the slow frequency oscillation phenomenon was presented for discussion for the first time. However, the torsional oscillation phenomenon in the turbine shaft has been recognized until 1970 at the Mohave power plant of southern Nevada of the USA [4,5]. In this year, a little before the event at Mohave plant, Rustebakke, Concordia published yet another paper drawing attention to the problem of selfexcited oscillations in series compensated transmission lines, but SSR was again missed. Finally, in 1973 a sound analysis of the self-excited torsional oscillations was present and foundations for the more advanced analysis methods of today were laid. Since then, a multitude of papers have been published in various journals and conference proceedings by applying many techniques such as bypass switch, passive filter, and Flexible AC Transmission system (FACTS) devices, in which FACTS technologies pose rival solutions to the modern power system in some terms such as increasing the power flow transfer capability, improving the continuous control over the voltage profile, enhancing the system damping, misnaming the losses, and specially mitigating SSR [6-10]

In order to mitigate SSR in the power system, the FACTS devices can be enhanced with auxiliary controller that provides the damping signal used as a best way. As yet, many countermoves have been employed as the shunt connected dynamic reactive power compensators introduced in $[8,9,11,12]$; the static VAR compensator (SVC) proposed in $[8,13]$; the static synchronous compensator (STATCOM) presented in [14]; the thyristor controlled series compensator (TCSC) applied in [10]; the static synchronous series compensator (SSSC) used in [15-18]; and the unified power flow controller (UPFC) proposed in [18]. However, SSSC's cost and complexity are very high; UPFC has a series and shunt converter so that it is more expensive and complex. Therefore, FACTS devices as TCSC, SVC, and STATCOM are an inevitable choice for mitigating the SSR.

The analysis performed for this study shows that the generator units of Vungang I are exposed to high SSR risk. The analysis shows the 2nd torsional mode to be unstable at low load under normal conditions, particularly when both units are online. In addition, according to the analysis of General Electric International, Inc., Energy Consulting Group, it recommends that the torsional protection be installed on both units as soon as possible to help prevent further failures. The generator units of Vungang I of Vietnamese power system are facing a high difficulty for SSR currently. As a result, the key is to propose a solution for mitigating SSR. As the above-mentioned points, the FACTS devices are an inevitable 


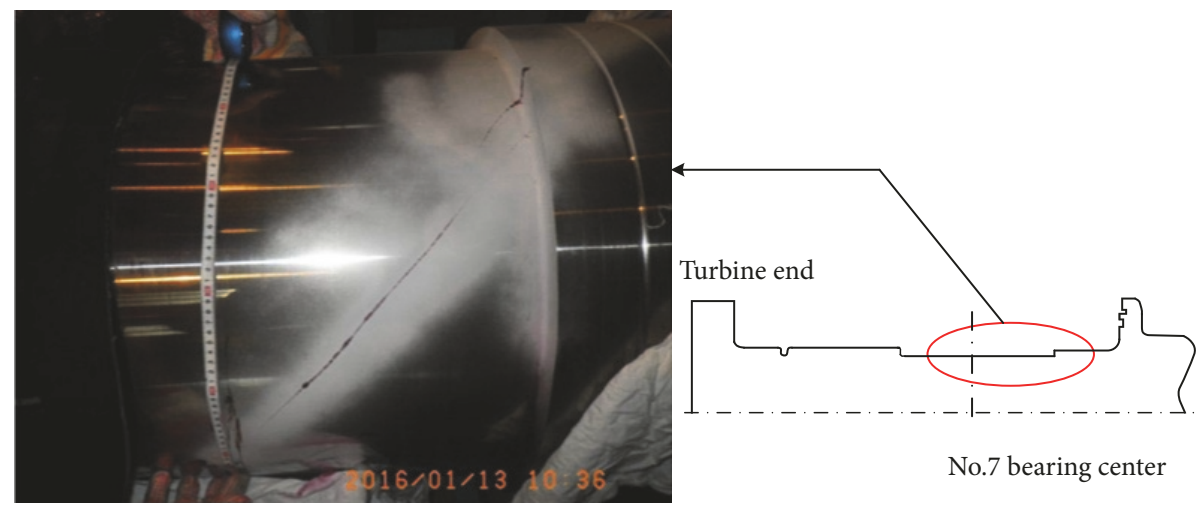

FIGURE 2: An example of cracks on No. 7 journal of Unit-1 generator.

choice. Therefore, this study presents the application of STATCOM, TCSC, and SVC devices to mitigate SSR for Vungang I and II thermal power plants, in which the used controller was modified from control units proposed in [1922]. The main contributions are (i) to develop a novel control strategy for each FACTS device for mitigating SSR in the power system and (ii) to propose SVC-FACTS; it is inevitable choice to solve the difficulties encountered in the Vietnamese power system.

The remainder of this paper is organized as follows: Section 2 analyzes the subsynchronous resonance for power system and a failure of Vungang I plant that occurred on Nov. 24,2015 , due to SSR is also carried out for analysis. Section 3 develops a control strategy for each of FACTS devices to mitigate SSR. The case studies and conclusions are given in Sections 4 and 5 , respectively.

\section{Subsynchronous Resonance Problem}

2.1. Characteristics of the Vungang Plants. The Vietnamese $500 / 220 \mathrm{kV}$ transmission system consists of 29 substations of $500 \mathrm{kV}, 162$ substations of $220 \mathrm{kV}, 16$ double-circuit lines and 20 single-circuit lines of $500 \mathrm{kV}, 205$ double-circuit lines and 67 single-circuit lines of $220 \mathrm{kV}$, and 179 generator units. The generated total power is about $42,179 \mathrm{MW}$; the peak load demand is about $40,703 \mathrm{MW}$. The single-line diagram and the result of load flow calculation on the $500 \mathrm{kV}$ voltage level are shown in Figure 3.

\subsection{System Modeling for Analyzing}

\section{Subsynchronous Resonance (SSR)}

Analysis of SSR. SSR is a state in which the power system exchanges the energy with the generator turbine at one or more frequencies below the synchronous one where the synchronous frequency is defined as the one corresponding to the rotor average speed. A turbine-generator supplying a series compensated system is considered as shown in Figure 4.
The electrical system subsynchronous natural frequency can be expressed as [4]

$$
f_{e}=f_{o} \sqrt{\frac{X_{C}}{X^{\prime \prime}+X_{T}+X_{L}+X_{s y s}}}
$$

where $f_{o}$ is the frequency corresponding to average rotor speed, $X^{\prime \prime}$ is the generator subtransient reactance, $X_{T}$ is the transformer reactance, $X_{L}$ is the transmission line reactance, and $X_{s y s}$ is the system reactance.

The frequency of armature current induced in the rotor windings is given by

$$
f_{r}=f_{o} \pm f_{e}
$$

The stator frequency is generated due to the variations in the rotor magnetic field and can be obtained as follows:

$$
f_{s}=f_{o} \mp f_{r}
$$

From (2) and (3), it can be realized that the oscillation of the generator rotor at the frequency $f_{r}$ can cause modulation of the terminal voltage, which results in a subsynchronous voltage component at $\left(f_{o}-f_{r}\right)$ and a supersynchronous voltage component at $\left(f_{o}+f_{r}\right)$.

Combined Generator and Shaft System. As shown in Figure 4, the mechanical system is modeled fully by a high-pressure stage (HP), an intermediate stage (IP), two low-pressure stages (LPA and LPB), the generator (GEN), and exciter (EXC) separately. The linearized state equations of combined generator and shaft system model are expressed as

$$
\begin{aligned}
& \Delta \dot{x}_{G}=\left[A_{G}\right] \Delta x_{G}+\left[B_{G}\right] \Delta u_{G} \\
& \Delta y_{G}=\left[C_{G}\right] \Delta x_{G}
\end{aligned}
$$

where $\Delta x_{G}$ is state vector and can be expressed in the following form:

$$
\begin{aligned}
& \Delta x_{G}^{t}
\end{aligned}
$$

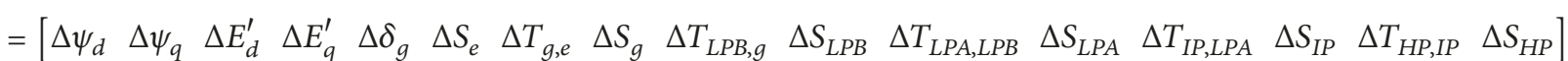




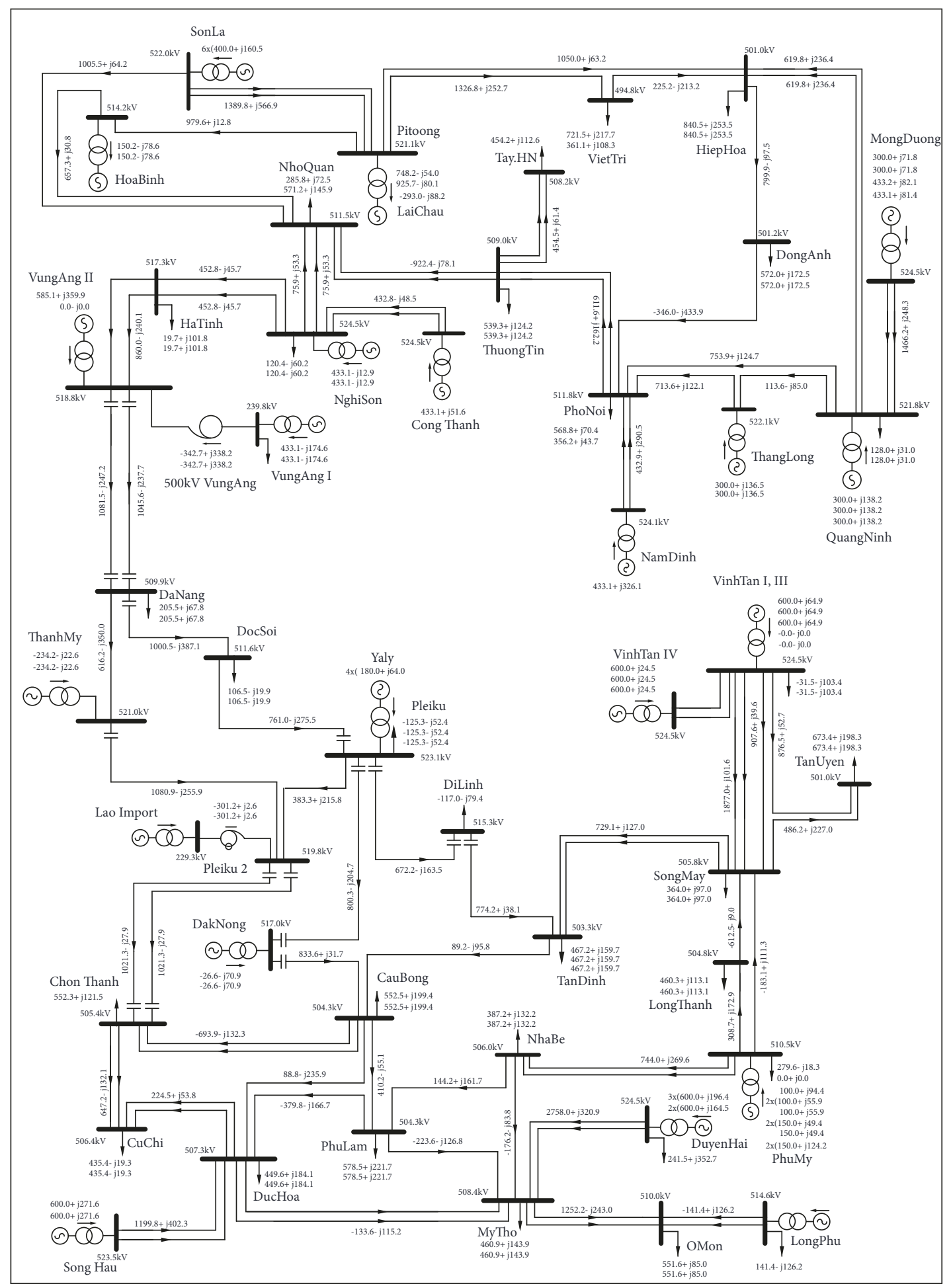

Figure 3: The result of load flow calculation on the Vietnamese $500 \mathrm{kV}$ power system 2020 for the maximum load requirement.

in which $\Psi$ denotes the stator flux linkage, $E^{\prime}$ denotes the transient internal voltage in the synchronous rotating $d q$ reference frame, $\delta$ is the rotor angle, $S$ denotes the per unit slip, and $T$ denotes the torque. $\Delta u_{G}$ is input vector containing the terminal voltages and $\Delta y_{G}$ is output vector containing the armature currents, applying the $D Q$ reference frame for the entire system, and can be expressed as follows, respectively:

$$
\begin{aligned}
& \Delta u_{G}^{t}=\left[\begin{array}{ll}
\Delta u_{D} & \Delta u_{Q}
\end{array}\right] \\
& \Delta y_{G}^{t}=\left[\begin{array}{ll}
\Delta i_{L D} & \Delta i_{L Q}
\end{array}\right]
\end{aligned}
$$




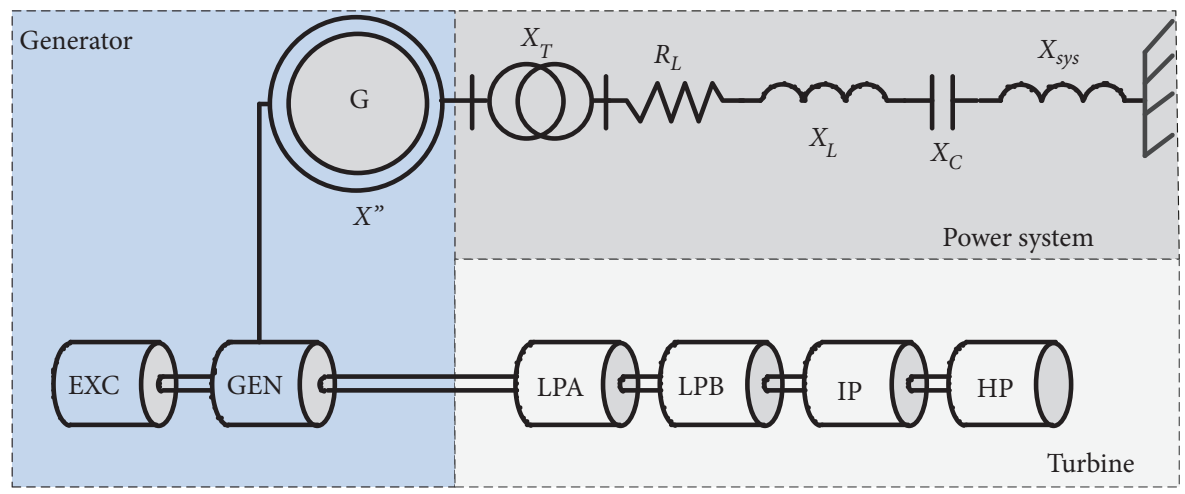

FIGURE 4: Electromechanical power system.

Network. The considered network shown in Figure 3, the linearized equation, can be expressed as follows:

$$
\begin{aligned}
\Delta \dot{x}_{N 1} & =\left[A_{N 1}\right] \Delta x_{N 1}+\left[B_{N 1}\right] \Delta y_{G} \\
\Delta u_{G} & =\frac{X_{L}}{\omega} \Delta \dot{y}_{G}+\left[F_{1}\right] \Delta y_{G}+\left[F_{s 1}\right] \Delta x_{N 1}+\Delta e_{1}
\end{aligned}
$$

where

$$
\begin{aligned}
X_{L} & =\omega L, \\
\Delta x_{N 1}^{t} & =\left[\begin{array}{ll}
\Delta u_{c D} & \Delta u_{c \mathrm{Q}}
\end{array}\right], \\
\Delta e_{1}^{t} & =\left[\begin{array}{ll}
\Delta u_{1 D} & \Delta u_{1 \mathrm{Q}}
\end{array}\right] \\
A_{N 1} & =\left[\begin{array}{cc}
0 & -\omega \\
\omega & 0
\end{array}\right], \\
B_{N 1} & =\left[\begin{array}{cc}
\omega X_{C} & 0 \\
0 & \omega X_{C}
\end{array}\right], \\
F_{1} & =\left[\begin{array}{cc}
R & X_{L} \\
-X_{L} & R
\end{array}\right], \\
F_{s 1} & =\left[\begin{array}{ll}
1 & 0 \\
0 & 1
\end{array}\right],
\end{aligned}
$$

2.3. Analysis of SSR for the Vungang Plants. The EMTP-RV program is used to analyze SSR Vungang I and II thermal power plants; we have to develop a linear model of the Vietnamese 500 and $220 \mathrm{kV}$ power systems based on the approach given in [23]. Vungang I and II coal thermal generators are modeled based on [24] and the data and performances based on TOSHIBA manufacturer.

Vungang I thermal power plant (TPP) is located in the Vungang industrial zone, Kyloi commune, Kyanh district, Hatinh province, in Vietnam consisting of two turbines with a total capacity of 1,200 MW. To improve the transferring capability as well as system stability, the fixed series capacitor is applied to the parallel transmission lines between Vungang power plant and Danang substation with 55 percent compensation level. The Vungang II TPP will be constructed close to
Vungang I consisting of two turbines with a total capacity of $1,200 \mathrm{MW}$. The first unit is expected to be operational in 2021 and the second one in 2022. Figure 5 illustrates the one-line diagram of the equivalent transmission system.

To test Vungang I and II plants about the SSR, frequency response of the Vietnamese power system configuration to the year 2020 was measured at generator terminal with 55 percent series compensation level of the reactance of the transmission network. The subsynchronous electrical frequency of the system is near about $28.7 \mathrm{~Hz}$ which is less than the nominal frequency of $50 \mathrm{~Hz}$; it can be seen in Figure 6. Therefore, the currents will be generated which are subsynchronous in nature at the frequency equal to $22.2 \mathrm{~Hz}$ (based on (2)) in the rotor and lead to the torque amplification. Figure 7 is FFT analysis of the torque of the shaft sections for the validation of resonant frequency within time interval of 4 to $5 \mathrm{sec}$ of Vungang I plant. It is clear from this figure that torsional mode $26 \mathrm{~Hz}$ is existent.

To evaluate the dangerous level of SSR for the generator units of Vungang I and II plants, this study considers two scenarios of short circuit faults that are set, respectively, at two fault points as shown in Figure 5 and the following case studies:

Scenario 1. Consider a three-phase-to-ground fault at $0.1 \mathrm{sec}$ on the $500 \mathrm{kV}$ Vungang-Hatinh transmission line close to the Vungang $500 \mathrm{kV}$ bus, cleared after $0.1 \mathrm{sec}$.

Scenario 2. Consider a three-phase-to-ground fault on the $500 \mathrm{kV}$ Vungang-Hatinh transmission line close to Hatinh $500 \mathrm{kV}$ bus, cleared after $0.1 \mathrm{sec}$

Case 1. The simulations were done on Scenario 1 and the compensation level $\mathrm{X}_{\mathrm{C}} / \mathrm{X}_{\mathrm{L}}$ is to 0.55 . The worst-case torque oscillations are experienced when two plants are running parallel. The dynamic performance of the turbine-generator shaft of Vungang I and II plants during and after clearing fault is plotted in Figure 8. This figure shows that when the fault is cleared, the large oscillations will be experienced between the different sections of turbine-generator shaft, where the torsional torque in GEN-LPB, LPB-LPA, and LPA-HIP shaft sections is depicted. This is a typical case of SSR and it can be readily seen that the torsional torque amplitudes between the 


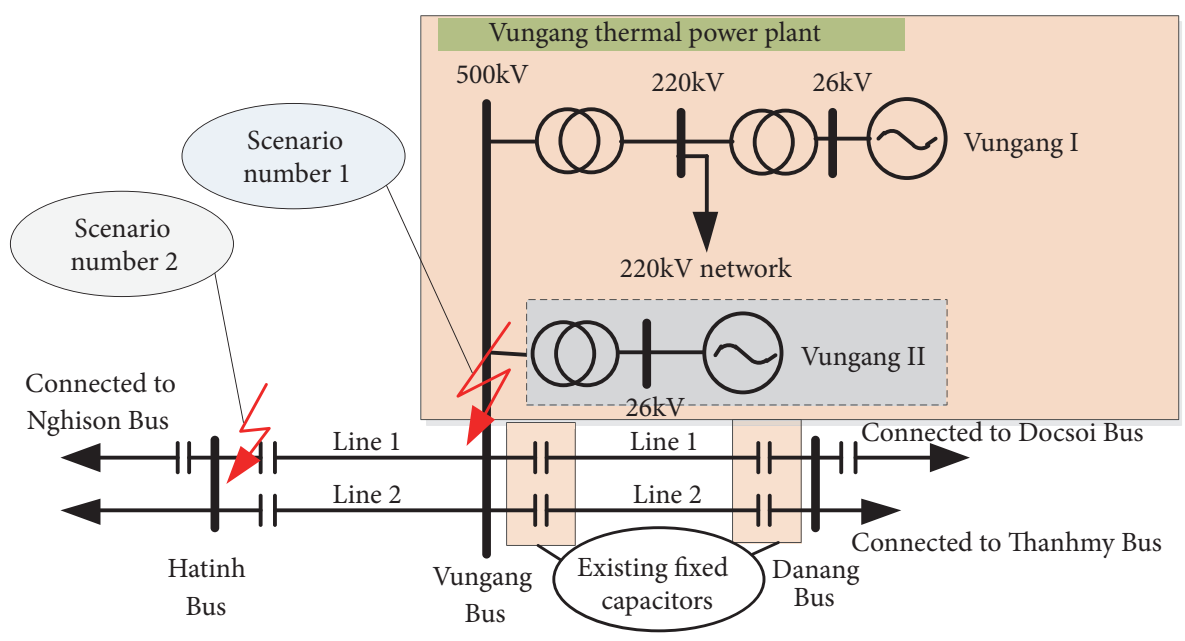

FIGURE 5: Connected circuit diagram of Vungang plants with $500 \mathrm{kV}$ power system model.

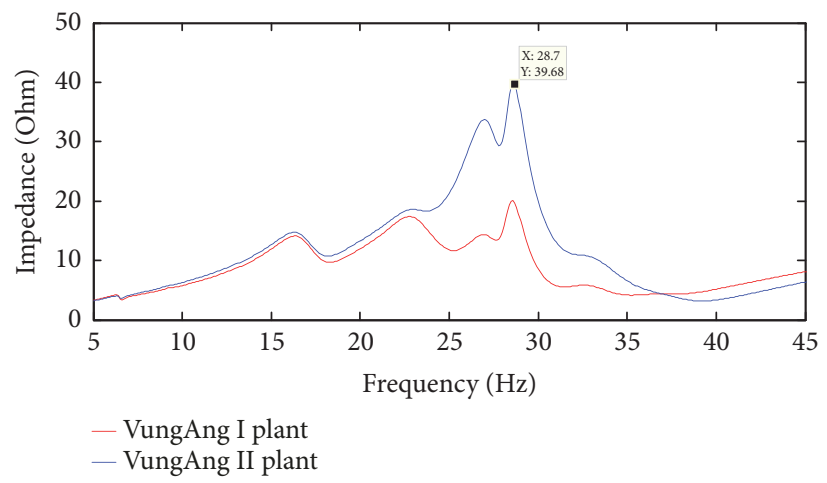

FIGURE 6: Frequency response of 55 percent compensated transmission network.

rotor shaft sections are very high and also their oscillations are growing with time. Such a transient has the potential to impair the rotor; especially if it becomes unstable leading to the generating unit outage and can affect the power system reliability.

Case 2. To further investigate the dangerous level of SSR for Vungang I and II plants, the simulations were done in this case based on Scenario 2 that a fault happened at a distance. The worst-case torque oscillations are experienced when two plants are running parallel. The results for the torque oscillations and rotor speed in this case with the compensation level $\mathrm{X}_{\mathrm{C}} / \mathrm{X}_{\mathrm{L}}$ being to 0.55 are shown Figures 9 and 10, respectively. From these figures, it can be clearly seen that the speed deviation in GEN, LPB, LPA, and HIP shaft sections of Vungang I plant's unit 1 and the torque in GENLPB shaft section of Vungang I and II plant's unit 1 during and after clearing fault are gradually increasing because of the presence of unstable mode in the system. Besides, according to the catalog of the manufacturer, the critical speed zone is a range from $800 \mathrm{rpm}$ to $2,700 \mathrm{rpm}$ as shown in Figure 11. Evidently, the rotor speed of turbine-generator exceeds the required limits. Hence, system is completely unstable leading to the faulted Vungang I plant's unit 1.
So, it can be concluded that even though the occurred fault is far from Vungang I plant, the SSR can happen due to the connection between two generator units of this plant and the transmission lines (Vungang-Hatinh and VungangDanang) through two 500/220 kV 450 MVA transformers. These transmission lines have the compensated rate of $55 \%$. In addition, according to a typical S (shaft torque)/ $\mathrm{N}$ (number of cycles) curve in [24], a fault exists on $0.1 \mathrm{sec}$, torque endurance magnitude between masses is 5 pu., and the existent required time does not exceed a few seconds. Thus, it needs a solution in order to mitigate SSR for Vungang I and II TPPs for maintaining the power system stability.

\section{The Proposed Solution}

As analyzed in Section 2, it can be seen that the SSR for Vungang's generator units might occur even though the occurred position of faults is distance for the connected position of Vungang plant I. As a result, these Vungang's generator units were unconnected to grid, leading to the instability of power system. In this case, there should be a positive solution for matter. The thyristor-controlled series capacitor (TCSC), static VAR compensator (SVC), and static synchronous compensator (STATCOM) are chosen as a good 


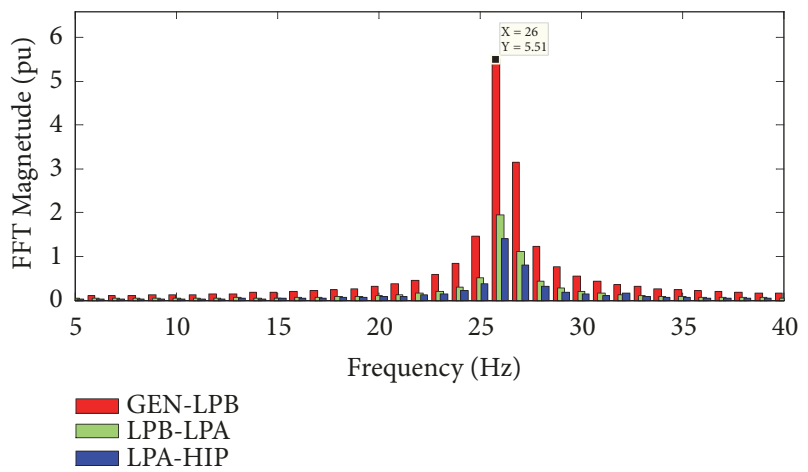

(a)

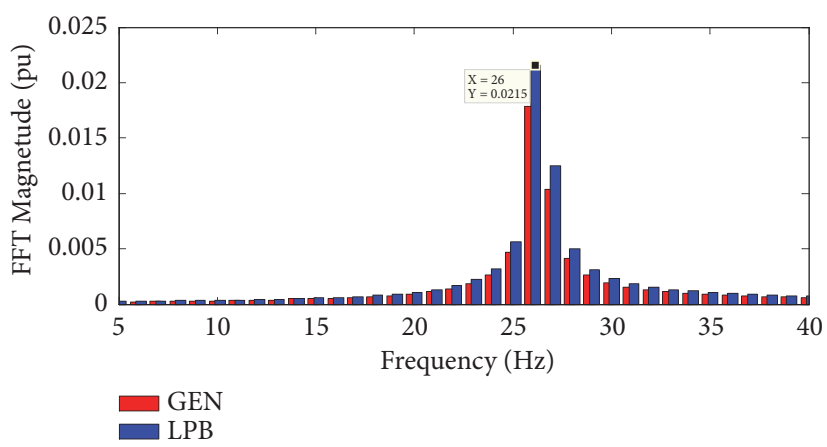

(b)

FIGURE 7: FFT analysis of shaft torque for the validation of resonant frequency: (a) GEN-LPB, LPB-LPA, and LPA-HIP shaft sections; (b) GEN and LPB shaft sections.

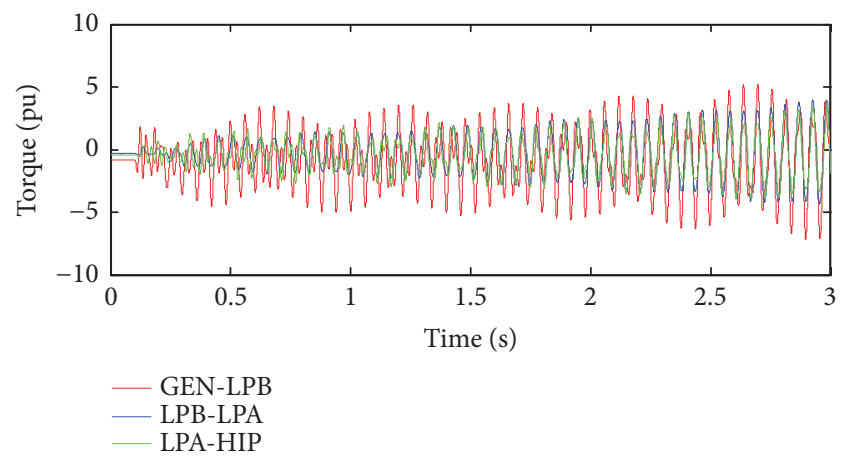

(a)

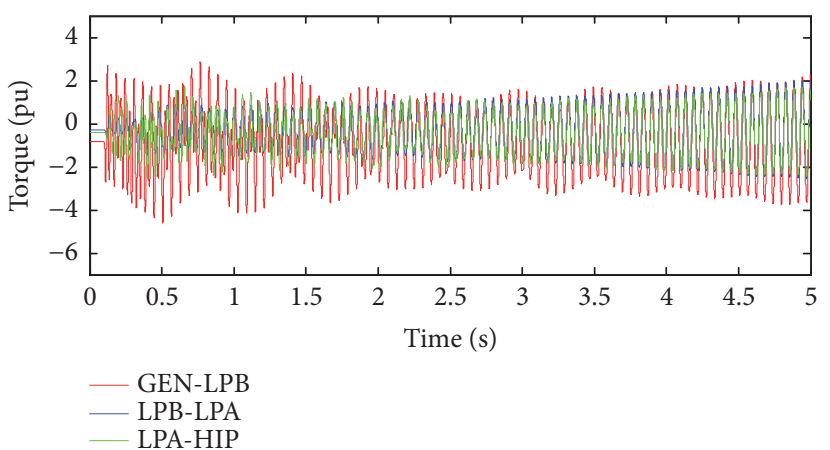

(b)

FIGURE 8: The torsional torque in GEN-LPB, LPA-LPB, and LPA-HIP shaft sections: (a) Vungang I plant's unit 1 during and after clearing fault and (b) Vungang II plant's unit 1 during and after clearing fault.

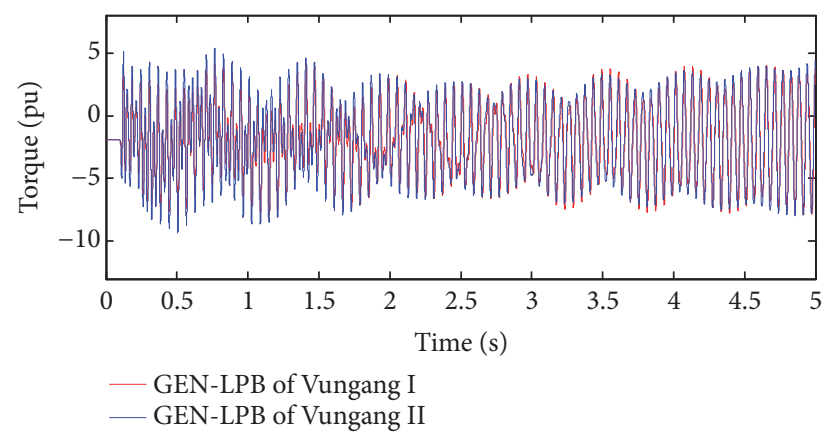

FIGURE 9: The torsional torque in GEN-LPB shaft sections of Vungang I and II plant's unit 1 during and after clearing fault.

solution. In this section, we analyze the control strategy for TCSC, STATCOM, and SVC.

3.1. Thyristor Controlled Series Compensator (TCSC) Device. The TCSC configuration is used to dampen SSR proposed in this paper as shown in Figure 12, which consists of a fixed series capacitor bank $C$ in parallel with a thyristor-controlled

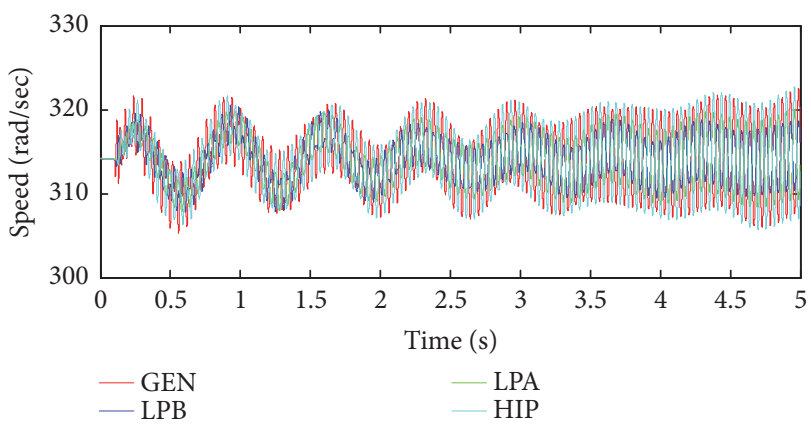

FIgure 10: The speed deviation in GEN, LPB, LPA, and HIP shaft sections of Vungang I plant's unit 1 during and after clearing fault.

reactor (TCR). When TCSC is operating in the mode without TCR it can be considered as the fixed series capacitor. In this case, subsynchronous behavior of TCSC is similar with fixed series capacitor with the same ratings. Thus, operation of TCR is required to change the subsynchronous behavior of TCSC so that the particular TCSC implementation depends on various structural and control system related factors. The 


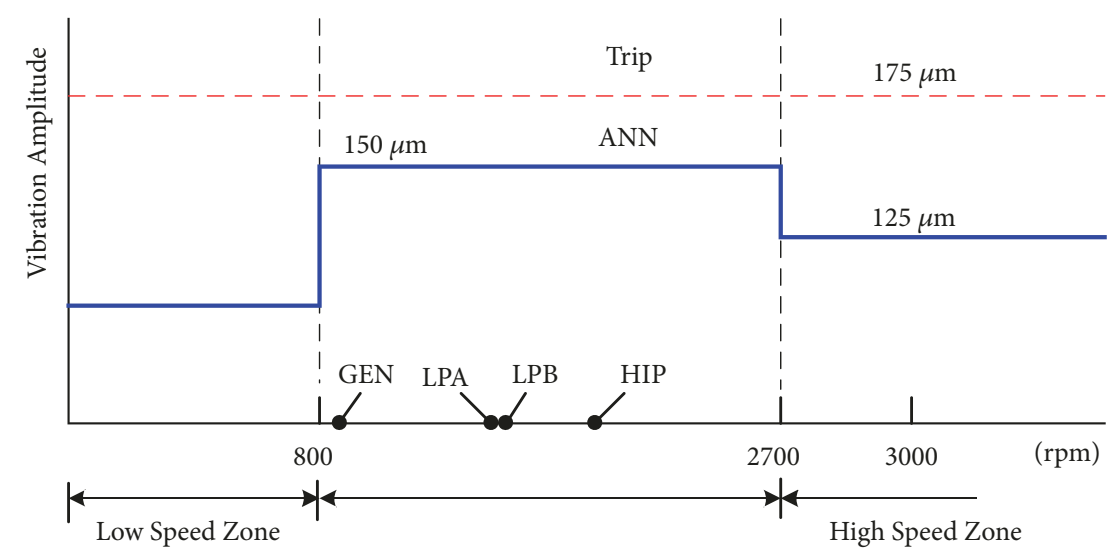

FIGURE 11: The rotating speed zone of generators.

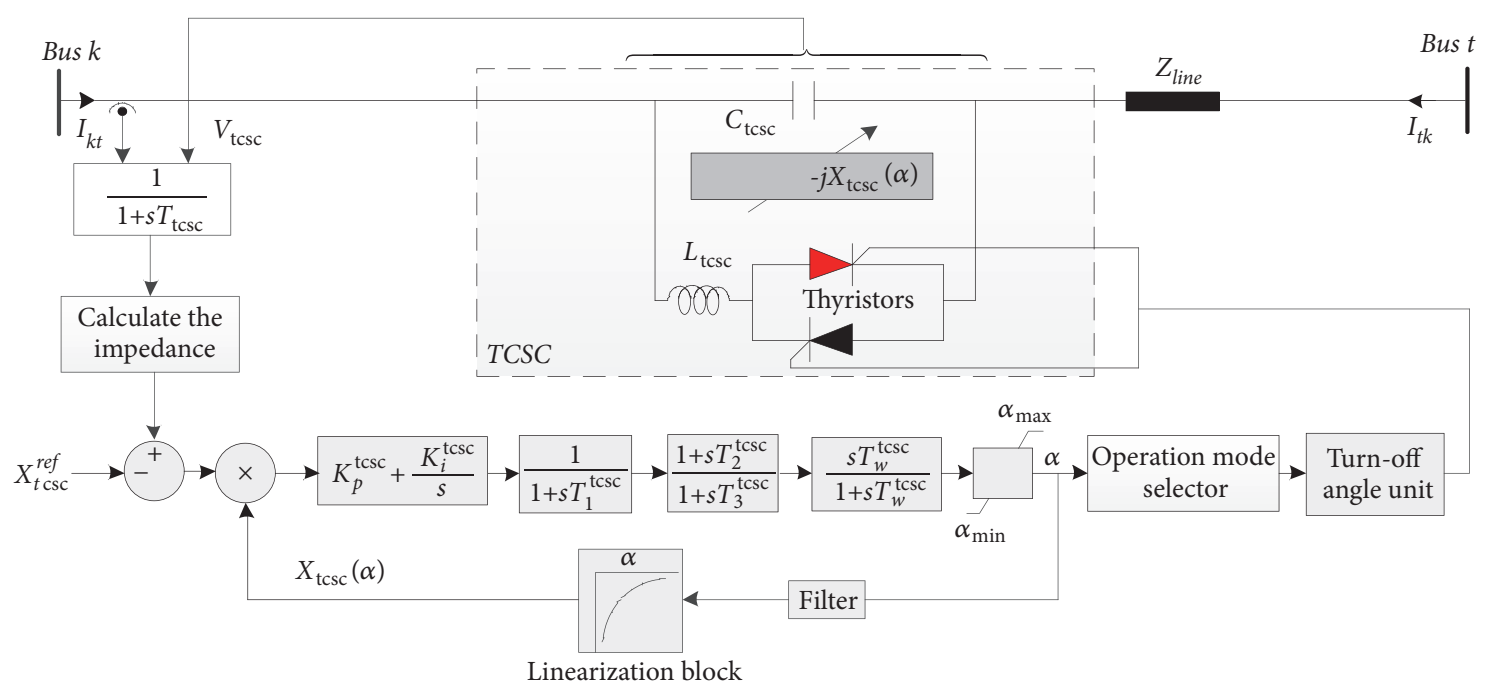

FIGURE 12: The control strategy for TCSC.

TCSC reactance is calculated in the following function of firing angle $\alpha$ :

$$
\begin{aligned}
& X_{T C S C}(\alpha)=X_{C_{\mathrm{tcsc}}}-\frac{k^{2} X_{C}}{\pi\left(k^{2}-1\right)}[2(\pi-\alpha) \\
& +\sin 2(\pi-\alpha) \\
& +\frac{4 k^{2} X_{C_{\mathrm{tscc}}} \cos ^{2}(\pi-\alpha)}{\pi\left(k^{2}-1\right)}[k \tan k(\pi-\alpha) \\
& -\tan (\pi-\alpha)]
\end{aligned}
$$

where $k=\sqrt{X_{C_{\mathrm{tscc}}} / X_{L_{\mathrm{tscc}}}}$ is the degree of series compensation. The effective reactance dependent on a parallel inductorcapacitor $(L C)$ at the fundamental frequency $f_{o}$, containing a fixed capacitive impedance, $\mathrm{X}_{\mathrm{Ctcsc}}=1 / 2 \pi f_{o} C_{\text {tcsc }}$, and an alterable inductive impedance $\mathrm{X}_{\text {Ltcsc }}=2 \pi f_{o} L_{\text {tcsc }}$ can be shown from (9). This variable $X_{\text {TCSC }}$ corresponding to the firing angle of the thyristors can be obtained by using the difference control strategies and feedback signal. In this paper, the main objective is to mitigate SSR. So the signal of the current of transmission line and voltage across TCSC are chosen to be used. The control strategy is shown in Figure 12, in which the product of the impedance error between the calculated and reference impedances and the output impedance of linearization block are passed through a PI controller. The output is the PI controller is passed through two lag/lead compensation blocks, a signal washout block, and a limiter block; then this signal enters the firing angle pulse generator. The operation mode selector block has only one task for setting a manual constant turn-off angle. In this paper, the TCSC controller is assumed to be operated in the reactive region between $0.25 X_{\text {line }}$ and $1.2 X_{\text {line }}$, where $X_{\text {line }}$ is reactance of transmission line where the TCSC is placed, the capacitor reactance at the fundamental frequency is chosen to be $X_{\text {Ctcsc }}=0.02 \mathrm{pu}$, and the TCSC ratio $X_{\text {Ctcsc }} / X_{L t c s c}$ is 10 . The parameters for TCSC controller are listed out in Table 1 using the genetic algorithm tool that is provided with the "optimum run" block in PSCAD. 


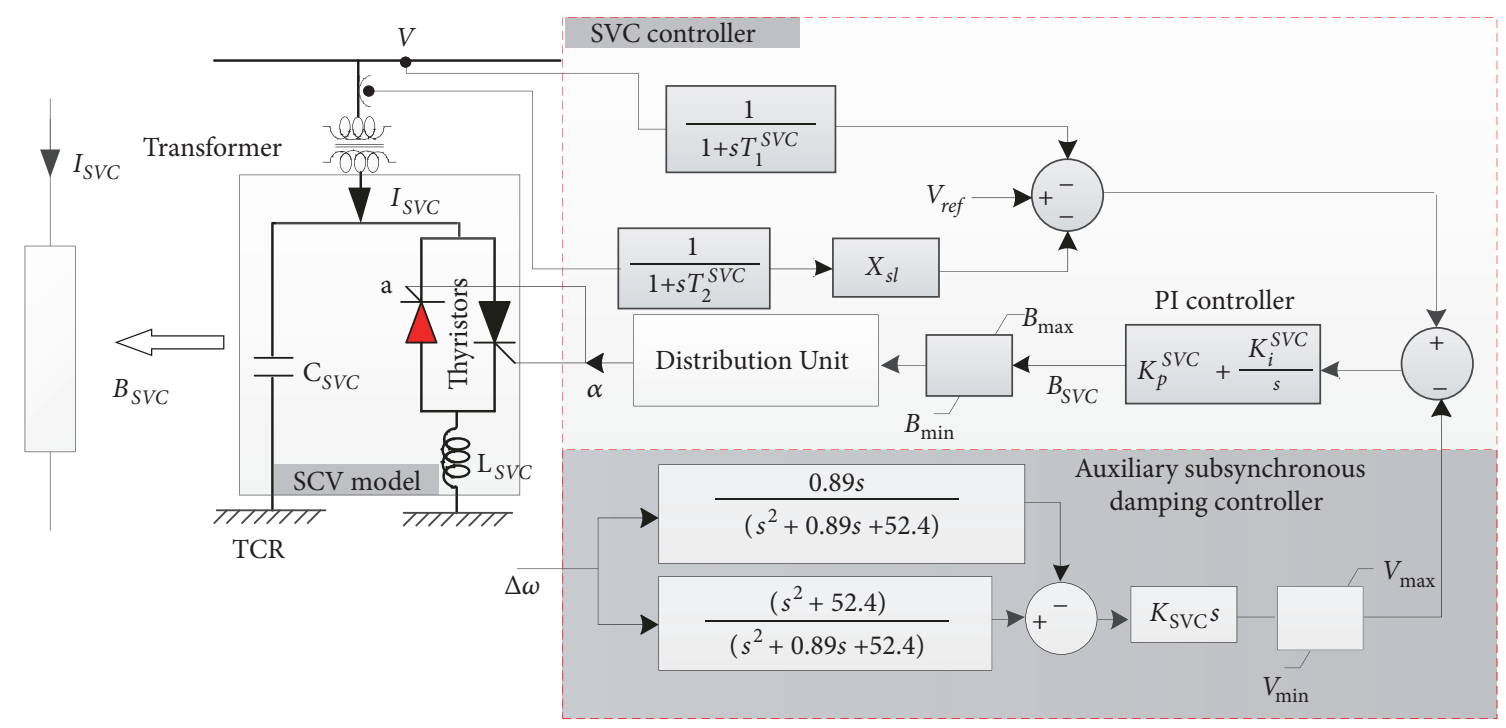

FIgURE 13: The control strategy for SVC.

3.2. Static VAR Compensator (SVC) Device. The SVC configuration is used to dampen SSR proposed in this paper as shown in Figure 13, in which the thyristor-controlled reactor (TCR) together with a fixed capacitor (FC) is connected in parallel and its controller. The proposed control strategy for SVC contains the auxiliary subsynchronous damping controller (SSDC) that is aimed using the generator rotor's angular speed deviation signal as the stabilizing signal. The voltage at connected point and the SVC's current are used as the control signal. Producing the voltage error signal, the voltage values (measured direct voltage and voltage through measured current with slope reactance) passing the washout blocks are compared with the reference voltage, and then this signal is compared with the obtained voltage from the auxiliary subsynchronous damping controller. The $B_{S V C}$ susceptance will be obtained by passing the voltage error through the PI controller. The TCR susceptance value obtained as function of the firing angle $\alpha$ can be presented as follows:

$$
B_{T C R}(\alpha)=\frac{2(\pi-\alpha) 4+\sin (2 \alpha)}{\pi}
$$

where the firing angle $\alpha$ is determined by passing $B_{S V C}$ through the distribution unit. The parameters for SVC controller are listed in Table 2.

3.3. Static Synchronous Compensator (STATCOM) Device. The STATCOM configuration is used to dampen SSR proposed in this paper as shown in Figure 14, which consists of a voltage source converter (VSC), a coupling transformer, a DC capacitor, and controller unit. The objective of this study is to investigate the SSR when the fault occurs in the system network. The control system is modified from the control strategy in [19]. The whole proposed control strategy is shown in Figure 14. It is compound of the voltage regulator with transient gain and can be determined by the time constants $T^{\text {stat }}$ and integrator $K$. The steady state gain
TABLE 1: The parameters of TCSC control system.

\begin{tabular}{lcc}
\hline Parameter name & Value & Unit \\
\hline$K_{p}^{\text {tcsc }}$ & 100 & - \\
$K_{i}^{\text {tcsc }}$ & 46 & - \\
$T_{T C S C}$ & 0.015 & $\mathrm{Sec}$ \\
$T_{1}^{\text {tcsc }}$ & 0.1 & $\mathrm{Sec}$ \\
$T_{2}^{\text {tcsc }}$ & 0.1 & $\mathrm{Sec}$ \\
$T_{3}^{\text {tcsc }}$ & 0.4 & $\mathrm{Sec}$ \\
$T_{w}^{\mathrm{tcsc}}$ & 10 & $\mathrm{Sec}$ \\
\hline
\end{tabular}

is equal to the inverse of Droop, allowing the sharing of voltage of generators. The input signals are the connected STACOM voltage $U_{b u s}$, reference voltage on the connected STATCOM bus $U_{r e f}$, the STATCOM internal voltage $U_{T}$, and the auxiliary signal. This auxiliary signal is generated by SSDC. The same as SVC, the proposed control unit for STATCOM also contains the auxiliary SSDC. The generator rotor's angular speed deviation signal is used as the stabilizing signal for the SSDC to generate the subsynchronous control output; this signal is passed through three separate control paths, comprising a band-pass filter, an amplifier, and a unitygain phase-shifter for each one. The objective of SSDC is to mitigate the multimodal SSR. The parameters of STATCOM are listed in Table 3 by using algorithms in $[19,25]$.

\section{Test Simulations}

According to the analysis in Section 2, it needs a solution in order to mitigate SSR for the Vungang I and II TPPs. The Vietnamese $500 / 220 \mathrm{kV}$ transmission system is mentioned in Section 2 with TCSC, SVC, and STATCOM and the proposed solutions in Section 3 have been simulated for further analysis. All dynamic models such as generators, excitation systems, transmission lines, and loads are modeled by using PSS/E (from dynamic model library) [26] and all dynamic 


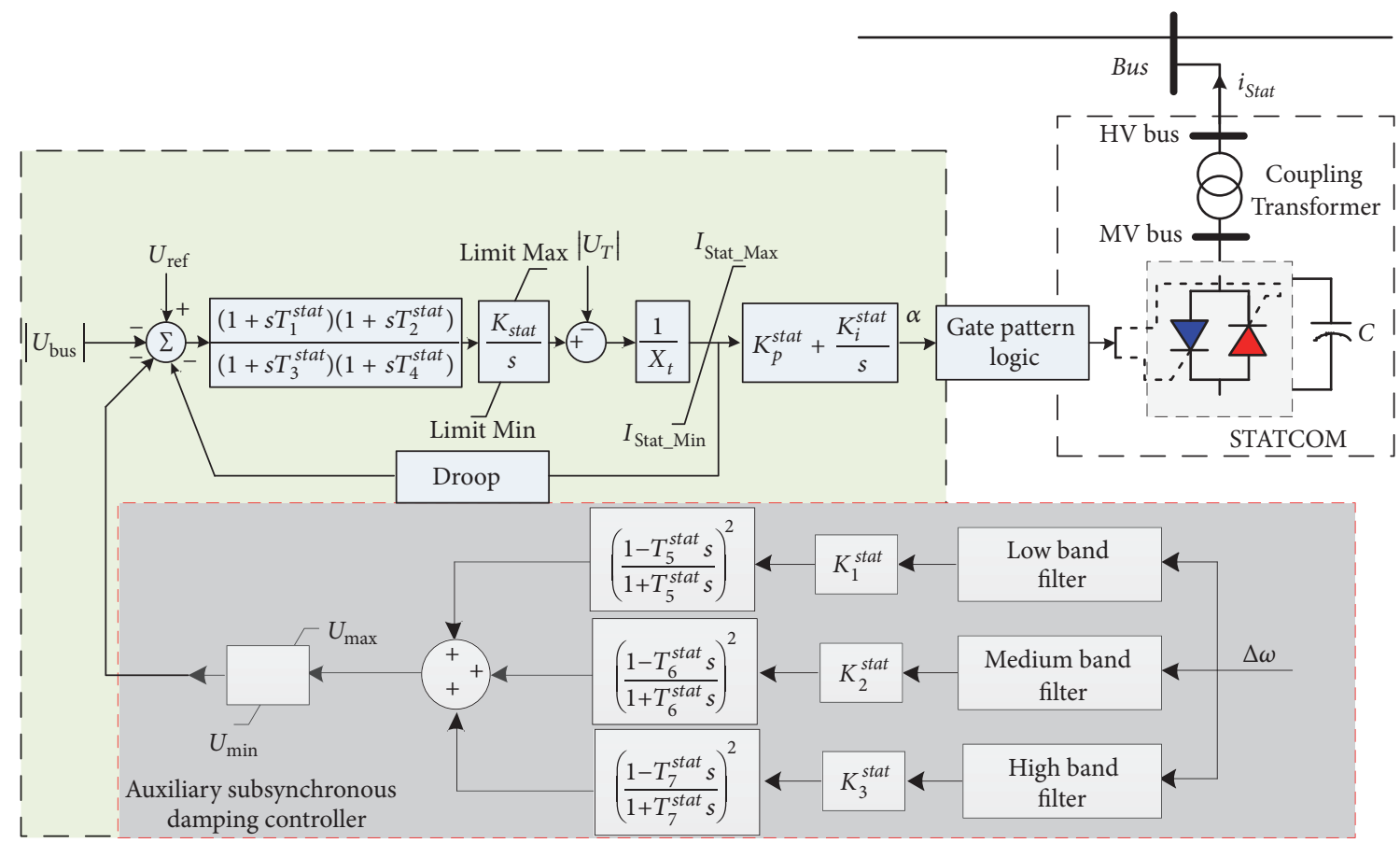

FIGURE 14: The control strategy for STATCOM.

TABLE 2: The parameters of SVC control system.

\begin{tabular}{lccccc}
\hline Parameter name & Value & Unit & Parameter name & Value & Unit \\
\hline$K_{p}^{s v c}$ & 2 & - & $V_{\max }$ & 1.2 & $\mathrm{pu}$ \\
$K_{i}^{s v c}$ & 85 & - & $V_{\min }$ & -1.0 & $\mathrm{pu}$ \\
$T_{1}^{s v c}$ & 0.1 & $\mathrm{Sec}$ & $B_{\max }$ & 1.0 & $\mathrm{pu}$ \\
$T_{2}^{s v c}$ & 0.178 & $\mathrm{Sec}$ & $B_{\min }$ & -1.0 & $\mathrm{pu}$ \\
$K_{s v c}$ & 400 & - & & \\
\hline
\end{tabular}

TABLE 3: The parameters of STATCOM control system.

\begin{tabular}{|c|c|c|c|c|c|}
\hline Parameter & Value & Unit & Parameter & Value & Unit \\
\hline$K_{\text {stat }}$ & 90 & - & $T_{6}^{\text {stat }}$ & 0.005 & $\mathrm{pu}$ \\
\hline$K_{p}^{\text {stat }}$ & 2 & - & $T_{7}^{\text {stat }}$ & 0.009 & $\mathrm{pu}$ \\
\hline$K_{i}^{\text {stat }}$ & 200 & - & $U_{\max }$ & 1.2 & $\mathrm{sec}$ \\
\hline$K_{1}^{\text {stat }}$ & -312 & - & $U_{\min }$ & -1 & $\mathrm{sec}$ \\
\hline$K_{2}^{\text {stat }}$ & 290 & - & $I_{\text {stat_Max }}$ & 1 & $\mathrm{sec}$ \\
\hline$K_{3}^{\text {stat }}$ & 210 & - & $I_{\text {stat_Min }}$ & -1 & $\mathrm{sec}$ \\
\hline$T_{1}^{\text {stat }}$ & 0.65 & sec & $X_{t}$ & 0.1 & $\mathrm{pu}$ \\
\hline$T_{2}^{\text {stat }}$ & 0 & $\mathrm{sec}$ & Limit Max & 1.2 & $\mathrm{pu}$ \\
\hline$T_{3}^{\text {stat }}$ & 0.3 & $\mathrm{sec}$ & Limit Min & -1.2 & $\mathrm{pu}$ \\
\hline$T_{4}^{s t a t}$ & 0 & $\mathrm{sec}$ & Droop & 0.02 & - \\
\hline$T_{5}^{\text {stat }}$ & 0.03 & $\mathrm{sec}$ & & & \\
\hline
\end{tabular}

parameters are taken from [27] and the Vietnamese national load dispatch center (NLDC). The single-line diagram and the result of load flow calculation are given in Figure 5. All the simulations are carried out in EMTP-RV environment for $55 \%$ compensation level.

The analysis of SSR with TCSC, SVC, and STATCOM devices is carried out based on damping torque analysis and transient simulation
4.1. Test Case with TCSC. In this case, the simulation was done on pondering upon the placement of existing fixed capacitors on the $500 \mathrm{kV}$ transmission line between buses Vungang and Danang by TCSC device. The detailed mathematical modeling, control strategy, and parameters of TCSC for mitigation of SSR have been proposed in Section 3.1. The robustness of the suggested TCSC controller as shown in Figure 12 and suggested parameters as listed in Table 1 is 


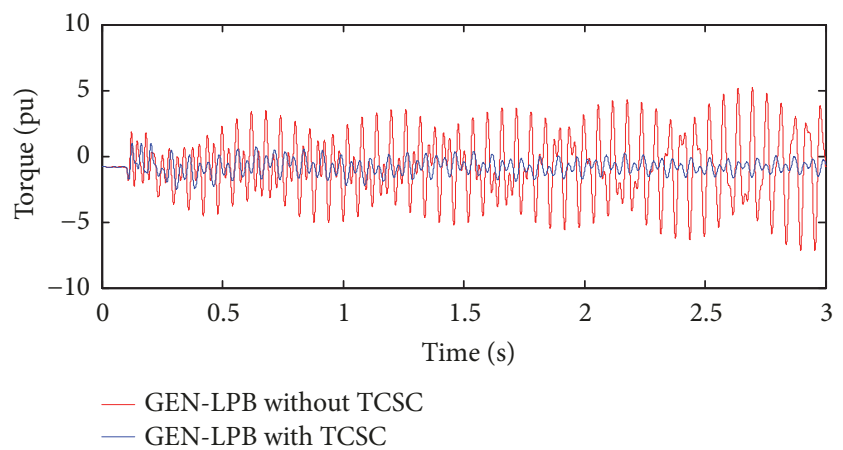

(a)

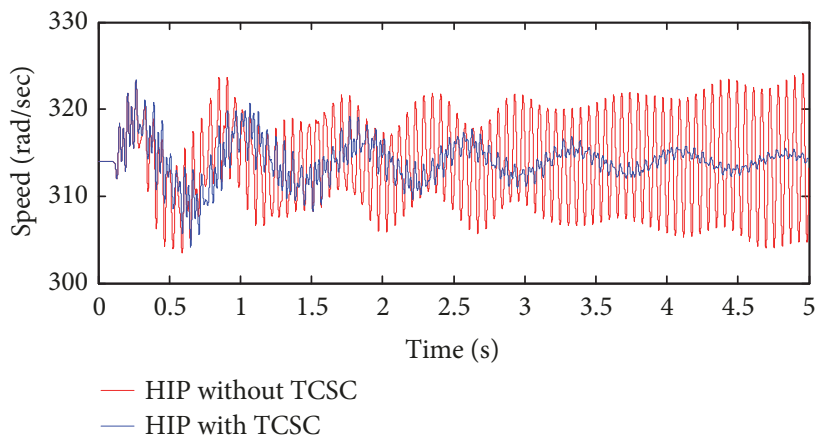

(b)

FIGURE 15: The effect of the TCSC on the SSR of Vungang II plant: (a) the torque oscillations in GEN-LPB shaft section of Vungang II plant's unit 2; (b) and the speed oscillations in HIP shaft section of Vungang II plant's unit 1.

investigated by considering a three-phase-to-ground fault at 0.1 sec on the $500 \mathrm{kV}$ Vungang-Hatinh transmission line close to the Vungang $500 \mathrm{kV}$ bus, cleared after $0.1 \mathrm{sec}$ (Scenario 1 is mentioned in Section 2.3). The simulation results are obtained and plotted in Figure 15. From this figure, it can be clearly seen that when the fault is cleared, the torque oscillations in GEN-LPB shaft section of Vungang II plant's unit 2 and the speed oscillations in HIP shaft section of Vungang II plant's unit 1 are very high and also their oscillations are growing with time in case using the fixed capacitors. This problem happened due to the unstable mode at $26 \mathrm{~Hz}$. These oscillations have greatly decreased when TCSC is connected to replace existing fixed capacitors. Compared with the inhibition effect of the existing fixed capacitors, the proposed control strategy of TCSC causes the torque and speed in shaft sections to dampen down in a shorter period. In addition, the maximal amplitude of the torque and speed in shaft sections is smaller, which can quickly suppress oscillation when SSR occurs, thus reducing damage to the generator shaft.

4.2. Test Case with SVC. For this case, the simulation was done on consideration for building SVC substation placed centrally on the $500 \mathrm{kV}$ Vungang-Danang transmission line and by passing the existing fixed capacitors at Vungang and Danang buses on the $500 \mathrm{kV}$ Vungang-Danang transmission line, and it can be shown in Figure 16. The detailed mathematical modeling, control strategy, and parameters of SVC for mitigation of SSR have been proposed in Section 3.2.

In order to assess the capability of the suggested SVC controller as shown in Figure 13 and the suggested parameters as listed in Table 2, the considered Scenarios 1 and 2 in Section 2.3 are utilized. The simulation results are obtained and plotted in Figure 17. From this figure, it can be clearly seen that when the fault is cleared, the torque oscillations in GENLPB, LPB-LPA, and LPA-HIP shaft sections of Vungang II plant's unit 2 have greatly decreased when SVC is connected. Thus, it could be concluded that the control strategy of SVC proposed in Section 3.2 has enough ability to mitigate SSR and the system becomes stable.
4.3. Test Case with STATCOM. In order to assess the capability of the suggested STATCOM controller as detailed in Figure 14 and the suggested parameters as listed in Table 3 for mitigating SSR, STACOM substation is placed centrally on the $500 \mathrm{kV}$ Vungang-Danang transmission line and bypassing the existing fixed capacitors at Vungang and Danang buses on the $500 \mathrm{kV}$ Vungang-Danang transmission line, and it can be shown in Figure 16 (replacing SVC substation). The simulation was done based on the torque oscillations in GENLPB and LPB-LPA shaft sections of Vungang I plant's unit 1 and Vungang II plant's unit 2 under considering Scenarios 1 and 2 , respectively. The simulation results are obtained and plotted in Figure 18. It can be clearly shown that when the fault is cleared, the torque oscillations in GEN-LPB and LPB-LPA have greatly decreased when STATCOM is connected. Thus, it could be concluded that the control strategy of STATCOM proposed in Section 3.3 has enough ability to mitigate SSR and the system becomes stable.

Based on the abovementioned analyses and the obtained results from three test cases, it can be shown that the SSR of Vungang PPTs is analyzed as the torque oscillation between shaft sections of generator rotor is greatly reduced when the three-phase short circuit fault in the power system occurs. From such a result, it could be concluded that the proposed solutions in Section 3 modified from the control strategies introduced in [19-22] for TCSC, SVC, and STATCOM, respectively, have secured mitigating SSR. As the expectation of this paper, it has to choose a better solution. In order to do that, a simulation was done based on the torque damped oscillations in GEN-LPB shaft section under considering the three-phase short circuit fault in the power system as mentioned in Scenario 1 to find one of the three proposed solutions that it has ability to withstand SSR better. The tested result is obtained and plotted in Figure 19. From this figure, it can be clearly seen that when the fault is cleared, the torque oscillations in GEN-LPB shaft section of Vungang II plant's unit 1 are damped better when using the proposed control strategy of SVC compared to one of TCSC and STATCOM. From such a result, it could be concluded that the control 


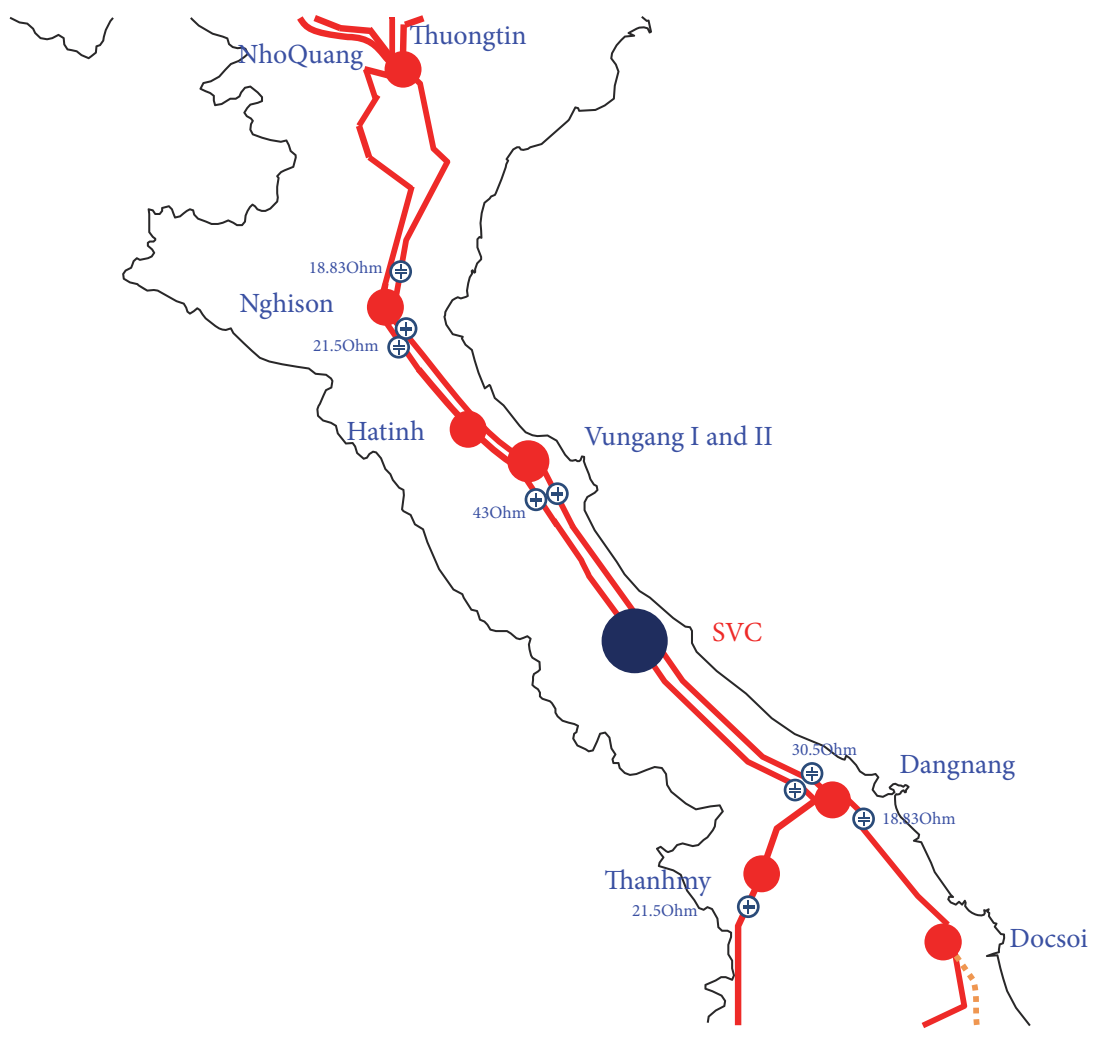

FIGURE 16: The location of placed SVC substation.

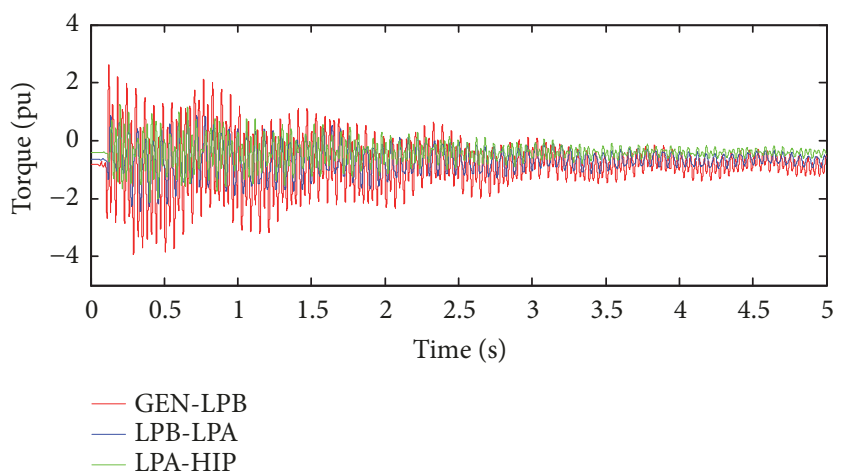

(a)

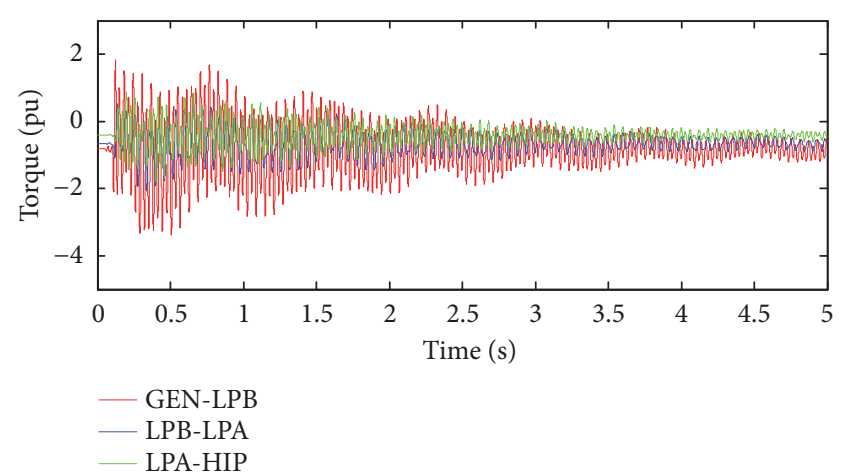

(b)

FIGURE 17: The effect of the SVC on the SSR of Vungang II plant: (a) the torque oscillations in GEN-LPB, LPB-LPA, and LPA-HIP shaft sections of Vungang II plant's unit 2 under considering Scenario 1; (b) the torque oscillations in GEN-LPB, LPB-LPA, and LPA-HIP shaft sections of Vungang II plant's unit 2 under considering Scenario 2.

strategy of SVC proposed in Section 3.2 has enough ability to mitigate SSR and the system becomes stable.

\section{Conclusions}

In this paper, the subsynchronous resonance (SSR) phenomenon for the power system has been analyzed. On the basis of that, this study analyzed an actual SSR event that has occurred in the Vietnamese Vungang I and II thermal plants on November 24, 2015. As a result, a shaft failure of Vietnamese Vungang I plant's unit 1 has occurred because of the series capacitors on the $500 \mathrm{kV}$ Vungang-Danang and Hatinh-Danang transmission lines. In order to solve the difficulties encountered in the Vietnamese power system, we have proposed the three difference control strategies by modifying the proposed control strategy in [19-22] for three FACTS devices as the thyristor-controlled series capacitor (TCSC), static VAR compensator (SVC), and static synchronous compensator (STATCOM). The time-domain simulation results on the transient analysis show that the SSR of Vungang PPTs is analyzed through the torque oscillation between shaft sections of generator rotor which is greatly 


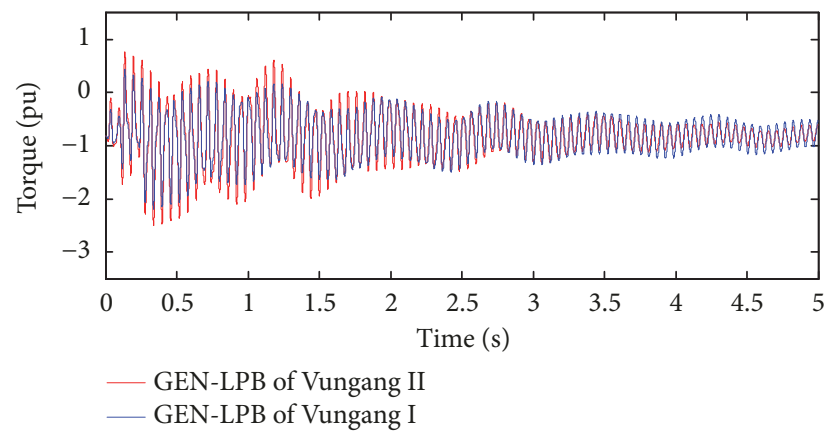

(a)

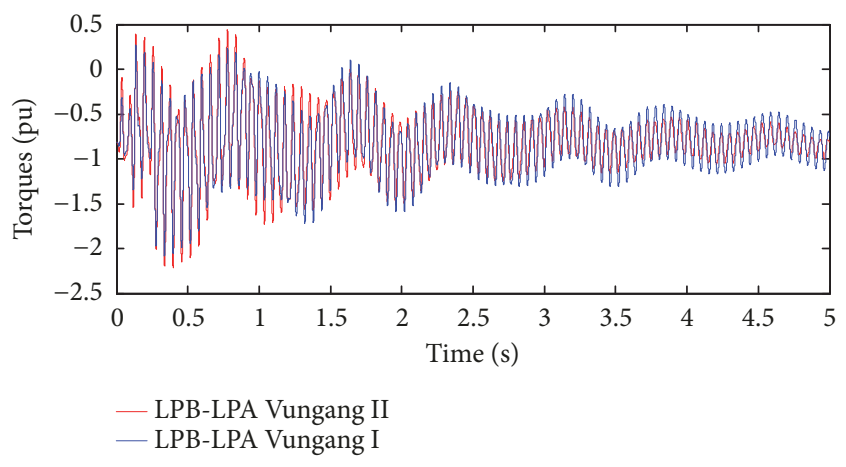

(b)

FIgURE 18: The effect of the STATCOM on the SSR of Vungang I and II plants: (a) The torque oscillation in LPA-LPB shaft section of Vungang I plant's unit 1 and Vungang I plant's unit 2 under considering Scenario 1. (b) The torque oscillation in LPA-LPB shaft section of Vungang II plant's unit 1 and Vungang I plant's unit 2 under considering Scenario 2.

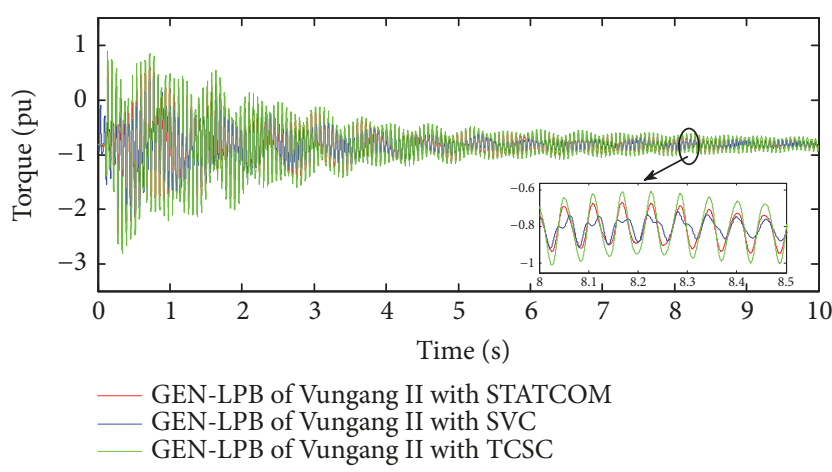

FIGURE 19: Comparison of the three proposed solutions.

reduced under the three-phase short circuit fault in the power system when using the proposed control strategies (three solutions). However, from the point of view of the power system stability, the control strategy has been proposed and designed for SVC device which has ability to mitigate SSR better than one for TCSC and STATCOM for the power system, particularly the Vietnamese power system.

In addition, for this study, the applied network is the Vietnamese 500/220 kV power system and SSR event of Vungang I plant's unit 1, the fixed series capacitor at Vungang, and Danang buses on the $500 \mathrm{kV}$ Vungang-Danang transmission line have been passed or revoked.

\section{Data Availability}

No data were used to support the study and all data are provided in full in the Results section of this paper.

\section{Conflicts of Interest}

The authors declare that there are no conflicts of interest regarding the publication of this paper.

\section{Acknowledgments}

The authors sincerely acknowledge the financial support provided by Ton Duc Thang and Industrial University of Ho Chi Minh City, Vietnam, for carrying out this work.

\section{References}

[1] R. M. Mathur and R. K. Varma, Thyristor-Based FACTS Controllers for Electrical Transmission Systems, John Wiley and Sons, 2002.

[2] C. Kreischer, S. Kulig, and C. Göbel, "Applicability of Park transformation for the analysis of transient performance during subsynchronous resonances," Archives of Electrical Engineering, vol. 62, no. 3, pp. 401-415, 2013.

[3] M. Orman, P. Balcerek, and M. Orkisz, "Effective method of subsynchronous resonance detection and its limitations," International Journal of Electrical Power \& Energy Systems, vol. 43, no. 1, pp. 915-920, 2012.

[4] J. Tang, R. Achilles, B. Agrawal et al., "Reader's guide to subsynchronous resonance," IEEE Transactions on Power Systems, vol. 7, no. 1, pp. 150-157, 1992.

[5] K. R. Padiyar, Analysis of Subsynchronous Resonance in Power Systems, Springer Science and Business Media, 2012.

[6] N. G. Hingorani and L. Gyugyi, Understanding FACTS: Concepts and Technology of Flexible AC Transmission System, IEEE Press, 2000.

[7] R. M. Mathur and R. K. Varma, Thyristor-Based FACTS Controllers for Electrical Transmission Systems Piscataway, John Wiley and Sons, 2002.

[8] A. E. Hammad and M. El-Sadek, "Application of a thyristor controlled var compensator for damping subsynchronous oscillations in power systems," IEEE Transactions on Power Apparatus and Systems, no. 1, pp. 198-212, 1984.

[9] N. C. Abi-Samra, R. F. Smith, T. E. McDermott, and M. B. Chidester, "Analysis of thyristor-controlled shunt SSR countermeasures," IEEE Transactions on Power Apparatus and Systems, vol. 3, pp. 583-597, 1985.

[10] W. Zhu, R. Spee, R. Mohler, G. Alexander, W. Mittelstadt, and D. Maratukulam, "An EMTP study of SSR mitigation using 
the thyristor controlled series capacitor," IEEE Transactions on Power Delivery, vol. 10, no. 3, pp. 1479-1485, 1995.

[11] T. H. Putman and D. G. Ramey, "Theory of the modulated reactance solution for subsynchronous resonance," IEEE Transactions on Power Apparatus and Systems, vol. PAS-101, no. 6, pp. 1527-1535, 1982.

[12] IEEE SSR working group, "Countermeasures to subsynchronous resonance problems," Transaction on Power Apatatus and Systems, vol. 99, no. 5, pp. 168-175, 1980.

[13] L. Gyugyi, "Fundamentals of thyristor-controlled static var compensators in electric power system applications," IEEE Special Publication 87TH0187-5-PWR, Application of Static Var Systems for System Dynamic Performance, pp. 8-27, 1987.

[14] K. Patil, J. Senthil, J. Jiang, and R. Mathur, "Application of STATCOM for damping torsional oscillations in series compensated AC systems," IEEE Transactions on Energy Conversion, vol. 13, no. 3, pp. 237-243.

[15] K. Sen, "SSSC-static synchronous series compensator: theory, modeling, and application," IEEE Transactions on Power Delivery, vol. 13, no. 1, pp. 241-246.

[16] G. N. Pillai, A. Ghosh, and A. Joshi, "Torsional interaction studies on a power system compensated by SSSC and fixed capacitor," IEEE Transactions on Power Delivery, vol. 18, no. 3, pp. 988-993, 2003.

[17] R. Thirumalaivasan, M. Janaki, and N. Prabhu, "Damping of SSR using subsynchronous current suppressor with SSSC," IEEE Transactions on Power Systems, vol. 28, no. 1, pp. 64-74, 2013.

[18] M. Bongiorno, L. Angquist, and J. Svensson, "A novel control strategy for subsynchronous resonance mitigation using SSSC," IEEE Transactions on Power Delivery, vol. 23, no. 2, pp. 10331041, 2008.

[19] L. Van Dai, D. D. Tung, and L. C. Quyen, "A highly relevant method for incorporation of shunt connected FACTS device into multi-machine power system to dampen electromechanical oscillations," Energies, vol. 10, no. 4, article 482, 2017.

[20] V. D. Le, X. Li, P. Li, and C. Q. Le, "A novel approach for determining optimal number and placement of static var compensator device to enhance the dynamic performance in power systems," Electrical Engineering, vol. 100, no. 3, pp. 15171533, 2018.

[21] L. van Dai, D. D. Tung, T. L. T. Dong, and L. C. Quyen, "Improving power system stability with Gramian matrix-based optimal setting of a single series FACTS device: feasibility study in Vietnamese power system," Complexity, vol. 2017, Article ID 3014510, 21 pages, 2017.

[22] V. Le, X. Li, Y. Li, Y. Cao, and C. Le, "Optimal placement of TCSC using controllability Gramian to damp power system oscillations," International Transactions on Electrical Energy Systems, vol. 26, no. 7, pp. 1493-1510, 2016.

[23] K. R. Padiyar, Power System Dynamics: Stability and Control, B.S. Publications, 2004.

[24] IEEE SSR working group, "First benchmark model for computer simulation of subsynchronous resonance," IEEE Transactions on Power Apparatus and Systems, vol. 96, no. 5, pp. 1565-1572, 1977.

[25] D. Zhang, X. Xie, S. Liu, and S. Zhang, "An intelligently optimized SEDC for multimodal SSR mitigation," Electric Power Systems Research, vol. 79, no. 7, pp. 1018-1024, 2009.

[26] Siemens PTI, "PSS/E 30.2 program operational manual," vol. 2, 2005.

[27] P. Kundur, Power System Stability and Control, McGraw-Hill, New York, NY, USA, 1994. 


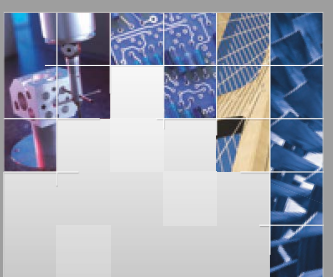

\section{Enfincering}
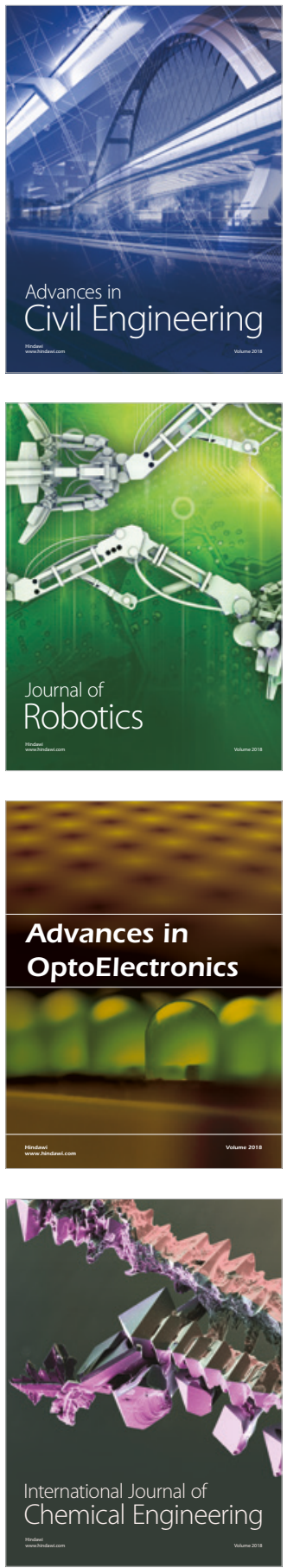

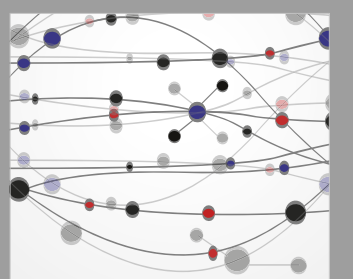

\section{Rotating \\ Machinery}

The Scientific World Journal

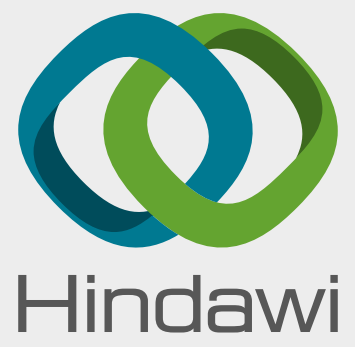

Submit your manuscripts at

www.hindawi.com
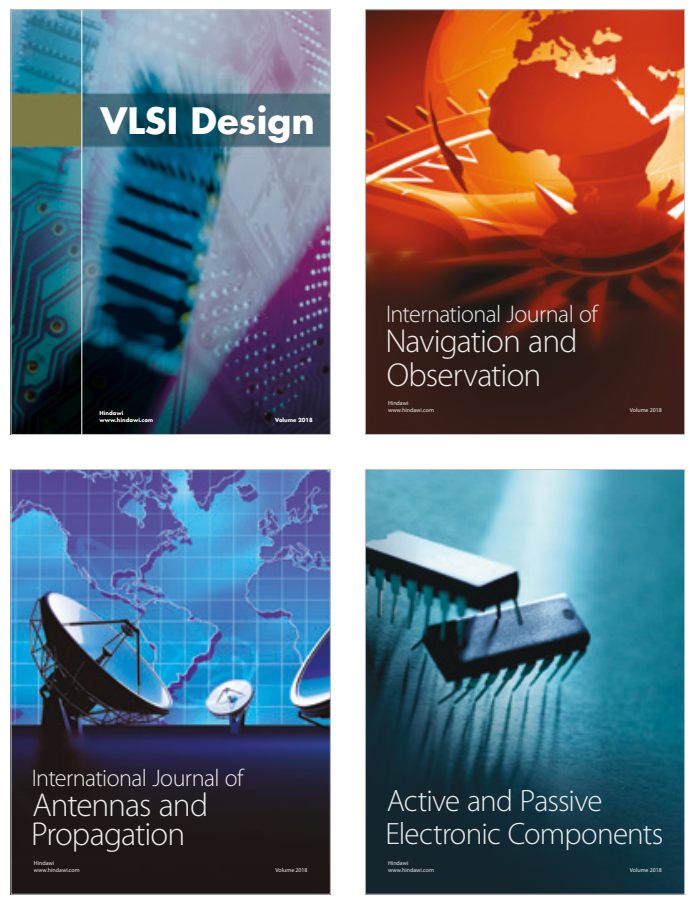
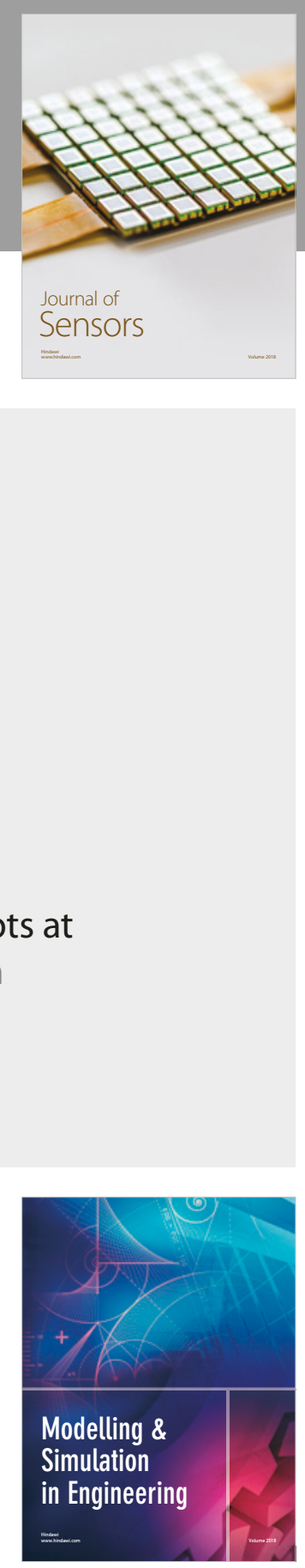

\section{Advances \\ Multimedia}
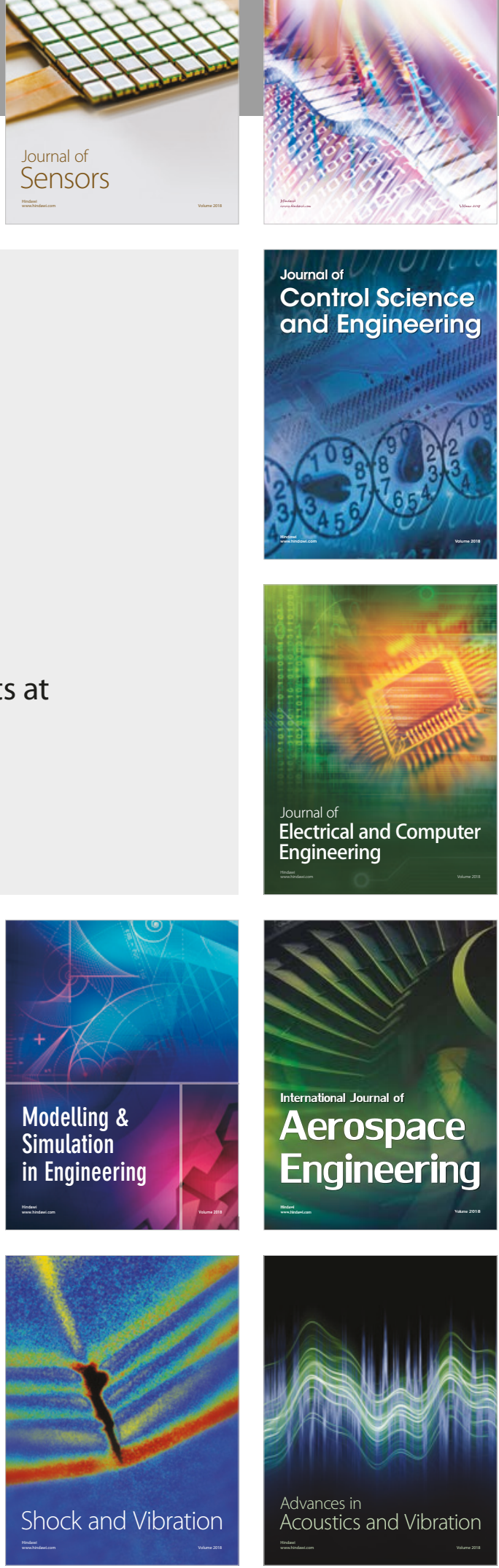